\title{
Recombinant Lactococcus lactis can make the difference in antigen-specific immune tolerance induction, the Type 1 Diabetes case
}

\author{
Sofie Robert ${ }^{1}$, Lothar Steidler ${ }^{2^{*}}$ \\ From 11th International Symposium on Lactic Acid Bacteria \\ Egmond aan Zee, the Netherlands. 31 August - 4 September 2014
}

\begin{abstract}
Especially in western civilizations, immune diseases that are driven by innocuous (auto- or allo-) antigens are gradually evolving to become pandemic threats. A particularly poignant example is type 1 diabetes, where young children are confronted with the perspective and consequences of total pancreatic $\beta$-cell destruction. Along these disquieting observations we find ourselves equipped with impressively accumulating molecular immunological knowledge on the ins and outs of these pathologies. Often, however, it is difficult to translate this wealth into efficacious medicines. The molecular understanding, the concept of oral tolerance induction, the benefit of using recombinant Lactococcus lactis therein and recent openings towards their clinical use may well enable turning all colors to their appropriate fields on this Rubik's cube.
\end{abstract}

\section{Antigen-specific immune therapy and recombinant Lactococcus, what, when and why}

(Auto-) immune diseases are characterized by aberrant immune reactions of the immune system towards a limited number of normally innocuous foreign antigens (Ags) as is the case for allergies and asthma or self-Ags in autoimmune diseases. More than 80 different autoimmune diseases have currently been identified. These can target only one organ, such as in type 1 diabetes (T1D), or multiple organs, such as in rheumatoid arthritis. Autoimmune diseases affect around $7 \%$ of the western population and this collective prevalence is increasing alarmingly $[1,2]$. A similar observation is seen for allergic diseases where the prevalence of $20 \%$ in children of developed countries also slowly rises [3-5]. The underlying events triggering this excessive reactivity remain unknown, but clearly involve genetic predisposition, allowing inapt interaction of environmental factors with the immune system. The general consensus to treat allergy and autoimmune diseases is altogether unsatisfactory. The field mostly relies on non-specific systemic

\footnotetext{
* Correspondence: lothar.steidler@actogenix.com

${ }^{2}$ ActoGenix NV, 9052, Zwijnaarde, Belgium

Full list of author information is available at the end of the article
}

immune suppression or symptomatic treatment which unfortunately does not address the underlying Ag-specific reactivity and is usually associated with severe systemic side effects. This can be overcome with Ag-specific therapeutic strategies targeting only the excessive immune reactivity. In this review we focus on Ag-specific tolerance induction in general and develop T1D as a case study for Ag-driven (auto-) immune diseases, to introduce Ag-specific tolerance restoration by oral administration of recombinant Lactococcus lactis (L. lactis) bacteria. This innovative Ag-specific strategy for oral tolerance induction could open up new therapeutic possibilities in the emerging field of (auto-) immune diseases. Moreover, it points to a clear opportunity where recombinant $L$. lactis could make the difference in medicine.

L. lactis' genetic engineering and the finding that it can be used for therapeutic protein delivery was developed during the previous century. The crux of the idea is that L. lactis can constitutively produce functional, eukaryote derived, proteins, without any apparent major negative effect on its growth and physiology, even when present in the mucosa of mammalians. The basics thereof are robust and sound and have changed little, as can be judged by a wealth of literature [6-14], all using 
the same basic principles. Now is an exciting time to find that the field has evolved in such a way that it has become a clinical option now considered by physicians [15]. The field is ready to address real-life demands and standards should be set along the existing standard of care. The aim of this review is to provide such benchmarking and to show that a viable clinical development path is realistic. Below we will elaborate on T1D as a genuine therapeutic need, review current treatment options, how Ag-specific therapies were conceptually molded and touch upon the possibilities and downsides of using oral tolerance induction. We will further develop our rationale by pointing out that recombinant L. lactis may well be the ideal tools to bring Ag-specific oral tolerance induction to reality, with focus on our recent findings in treating animal models of T1D. Finally, we will give a general overview of our accomplishments in clearing the clinical path for recombinant L. lactis.

\section{Type 1 diabetes}

T1D is an eminent example of a well-studied chronic autoimmune disease characterized by the selective destruction of insulin-producing pancreatic $\beta$-cells by pathogenic self-reactive $\mathrm{CD} 4^{+}$and $\mathrm{CD} 8^{+} \mathrm{T}$ cells. The prevalence of T1D is estimated to number up to more than 20 million patients worldwide with the incidence in children under the age of 5 to double between 2005 and $2020[16,17]$. With the help of several in vivo models, such as the biobreeding rat and the non-obese diabetic (NOD) mouse, both of which develop T1D spontaneously, more insight has been gained in the mechanism of the autoimmune cascade. Due to speculative triggers, pancreatic $\beta$-cell Ags become presented by Ag-presenting cells that have infiltrated pancreatic islets (Figure 1) $[18,19]$. This will activate and expand pathogenic islet Ag-specific T cell populations $[19,20]$ and eventually the natural balance between auto-reactive $T$ cells and their regulatory counterparts is disturbed, leading to tolerance breakdown and a progressive $\beta$-cell loss (Figure 1). The immanent diminished release of the glucose-regulating hormone insulin will lead to elevated blood glucose levels or hyperglycemia. As for most autoimmune diseases there is no specific cure for T1D. Patients can only rely on exogenous insulin substitutions to normalize glucose levels, which however do not prevent complications of the pathology, thereby making it difficult to pursue normal life quality and normal lifespan.

\section{Standard of care: systemic immune suppression, which comes at a price}

So far, current therapeutic strategies applying systemic immunosuppression have given the best results in clinical studies. Systemic immunomodulators, such as cyclosporine A and monoclonal anti-CD3 antibodies, target the general immune system in order to neutralize the $\beta$-cell-specific autoimmune reactivity.

Cyclosporine A, a pioneer amongst immunosuppressive agents, blocks immunity at one of its most crucial steps. This polypeptide inhibits $\mathrm{T}$ cell activation by inhibiting autocrine IL-2 synthesis and thus cell proliferation. The drug has already demonstrated efficacy in enhancing renal transplantations and preventing rejections [21]. Several clinical studies in newly-diagnosed type 1 diabetic patients showed disease remission associated with enhanced preservation of $\beta$-cell function by cyclosporine treatment [22-24]. However diabetes reversal was never sustained and was accompanied with severe forms of nephrotoxicity [25-27].

Monoclonal anti-CD3 antibodies, targeting the $\mathrm{T}$ cell receptor (TCR), are a unique class of immunomodulators in that they interact with both pathogenic effector $\mathrm{T}$ cells and regulatory $\mathrm{T}$ cells (Tregs, $\mathrm{T}$ cells that sustain tolerance). This dual mechanism of action works in two phases. In a first phase, recently activated $\mathrm{T}$ cells are transiently depleted or made blind to Ag by shedding and internalization of the TCR/anti-CD3 complex $[28,29]$. In a second, long-term phase, anti-CD3 antibodies preserve and induce Tregs [30,31]. In recently-diagnosed (early) diabetic NOD mice a short-term low-dose course of anti-CD3 at a total dose of $25 \mu \mathrm{g}$ could reverse diabetes in $80 \%$ of the treated mice $[32,33]$. These promising preclinical studies have led to construction of two humanized anti-CD3 antibodies, namely hOKT3y1 (Teplizumab) and ChAglyCD3 (Otelixizumab) and their clinical testing in newly-diagnosed type 1 diabetic patients [34,35]. Both drugs could preserve $\beta$ cell function for up to one year, after which the $\beta$-cell destruction gradually continued [36-38]. A follow-up study of Otelixizumab showed a significant preservation of $\beta$-cell function for up to 4 years post-treatment [39]. Increasing administered doses of Teplizumab with $40 \%$ did not ameliorate therapeutic efficacy and was associated with increased presentation of drug-related side effects, such as cytokine release, headaches, fever and rash [40]. In the Otelixizumab trial, several patients experienced a transient and self-limited reactivation of the Epstein-barr virus. However due to the positive therapeutic outcomes several phase III studies were conducted. The DEFEND-1 study, using Otelixizumab, did not meet its primary endpoint, mainly due to the unsubstantiated choice of validation parameters in addition to ad random choices made in dose reductions [41]. A second phase III study with Teplizumab (The Protégé study) also missed its primary endpoint. However, post-hoc analyses in subgroups of patients revealed better preservation of $\beta$-cell function when anti-CD3 was given in a full dose regimen, namely $17 \mathrm{mg}$ administered at baseline and again after 6 months $[42,43]$. Similar observations of preserved insulin 


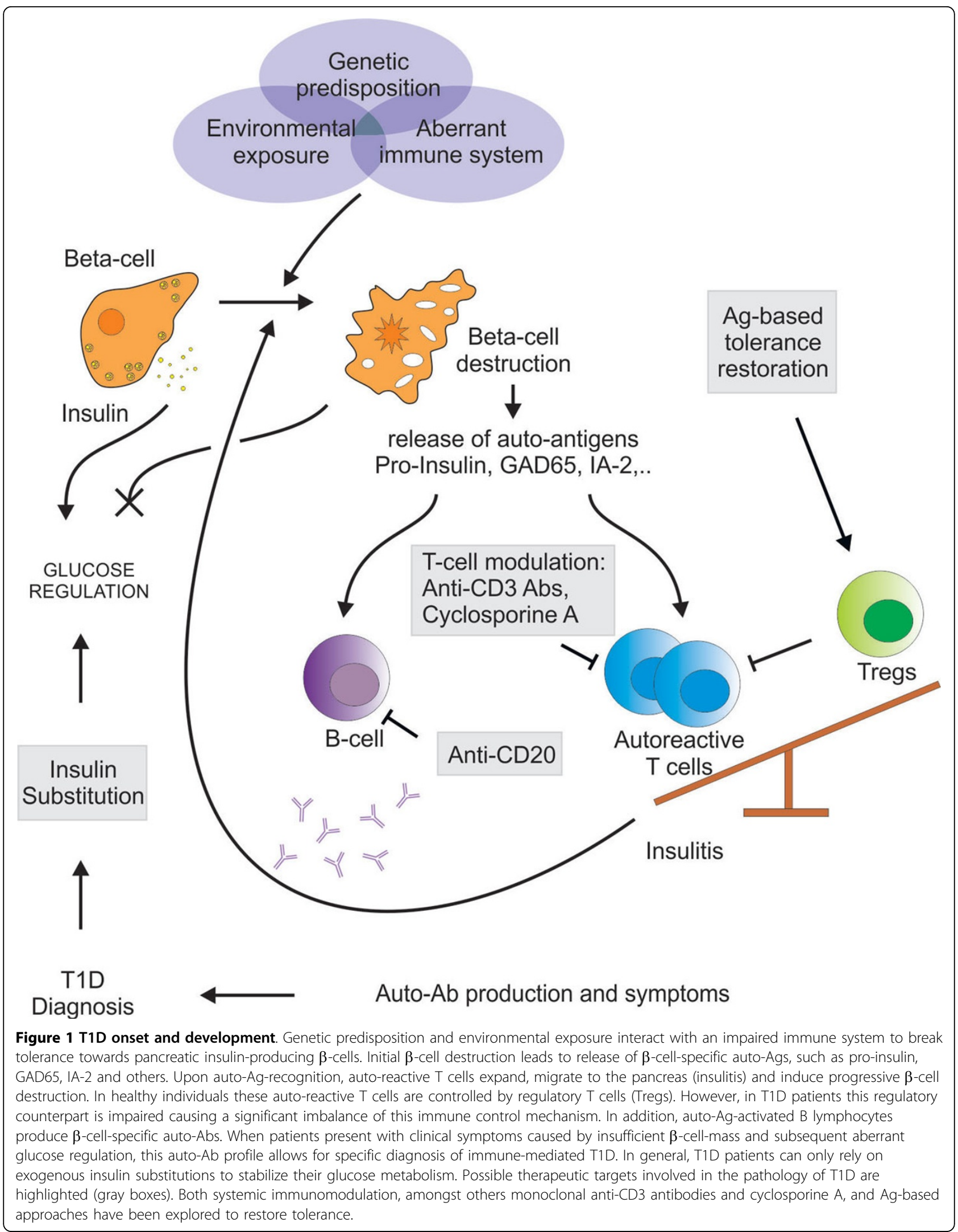


production with high-dose anti-CD3 were seen in the Autoimmunity-Blocking Antibody for Tolerance in Recently Diagnosed Type 1 Diabetes (AbATE) study [44]. Although the DEFEND-2, Protégé Encore and the SUBCUE trial were terminated, several investigator-led clinical studies with anti-CD3 are still being conducted. The At Risk-study is designed to evaluate whether teplizumab can help to prevent or delay disease onset in relatives at risk for T1D (http://ClinicalTrials.gov Identifier NCT01030861). The Delay-study evaluates whether Teplizumab will prevent the loss of insulin secretory capacity in individuals with recent, but not recent-onset, T1D (http://ClinicalTrials.gov Identifier NCT00378508). Also, a Phase I study on subcutaneous administration of Otelixizumab in T1D patients is ongoing (http://ClinicalTrials.gov Identifier NCT00946257). Taken together, these data still support anti-CD3 progress to full-scale phase III trials.

Although Ag-nonspecific systemic immune approaches have shown some therapeutic efficacy in the context of T1D - $\beta$-cell preservation, postponing the gradually decline in insulin production - one cannot but acknowledge that sustainable long-term effects could not be achieved. In addition, non-specific immune targeting provokes severe systemic side effects. Broad immune suppression renders the treated patient highly susceptible for pathogenic infections and may lead to the formation of malignancies. Notwithstanding the beneficial effects achieved with systemic immunomodulators, legitimate health risks remain associated with such therapeutic strategies. In conclusion it is fair to state that the shortcomings of current approaches limit access to effective therapies.

\section{Experimental Ag-specific T1D therapies are safe but show lack of efficacy}

In most (auto-) immune diseases immune reactivity is restricted towards a limited number of (auto-) Ags. Auto-Ags targeted by auto-reactive $\mathrm{T}$ cells are continuously emerging and their disclosure relies heavily on the identification of autoantibodies present in patients or disease-predisposed individuals. Ag-specific control of these auto-reactive $\mathrm{T}$ cells remains the ultimate therapeutic approach, eliminating the risk of any unwanted systemic immune reaction.

Ag-specific approaches for (auto-) immune diseases require careful consideration. Introducing selected (auto) Ags to a non-tolerogenic, already primed environment can boost (auto-)immune reactivity and aggravate disease. Correct choice of Ag, timing (window of opportunity), dose and frequency of administration are key aspects to take into consideration [45]. Accurate extrapolation of these parameters from preclinical animal, murine and porcine, models to man however remains a challenging task. Extrapolation should not just rely on mere body weight calculation but needs to take into account different physiological parameters, amongst others energy metabolism and renal function. Profound pharmacokinetic and pharmacodynamic studies in different animal models need to be carefully conducted to prevent unexpected events. Proper choice of adjuvants can favor a tolerogenic response. One example is the use of aluminum salts, which effectuates a Th2 response on top of enhanced Ag delivery and activation of Ag-presenting cells $[46,47]$. Moreover, the mode of administration remains crucial for tolerance inducing strategies.

Several pancreatic islet auto-Ags are involved in the pathogenesis of T1D, of which (pro-)insulin, glutamic acid decarboxylase 65 (GAD65) and tyrosine phosphatase-like protein ICA152 (IA-2) are the most prominent [48-50]. Parenteral, oral or nasal administration of said auto-Ags could prevent or delay T1D in the NOD mouse model underlining the prophylactic potential of Ag-specific therapies [51-55]. None of these preclinical studies were effective in established disease. So far, apart from a few exceptional cases dealing with cryptic epitopes, none of these preclinical studies have shown exacerbation of the autoimmune response, thereby highlighting their safe profile [56]. Hence, clinical translation has been disappointing. Multiple studies administering subcutaneous or intranasal insulin or GAD65 to newly-diagnosed T1D patients or to autoantibody-positive T1D-relatives did not improve the clinical outcome [57-62]. One study administering unprotected oral insulin induced a delayed onset of T1D, albeit only in a subgroup of diabetes-prone individuals with high baseline insulin autoantibodies [60]. Despite the disappointing absence of clinical efficacy, none of these clinical studies showed signs of disease aggravation, again reiterating the inherent safety of using these selected Ags.

\section{Oral tolerance induction: silver bullet, unmined field or the ever promise?}

A number of studies point to the mucosal immune system of the gastrointestinal tract to induce Ag-specific suppression, relying on its privilege to induce tolerance to orally administered Ags. The lymphoid tissue of the gut covers more than $260 \mathrm{~m}^{2}$ and contains one of the highest numbers of lymphocytes, rendering it the largest immune organ of the body. This mucosal immune system is excellently equipped to judge on unresponsiveness towards intestinal commensals and harmless food Ags and responsiveness towards pathogens. To maintain intestinal homeostasis, anti-inflammatory cytokines such as TGF- $\beta$ and IL-10 are abundantly present in the gut and together with retinoic acid they create a highly tolerogenic environment [63]. In addition, excessive mucosal production and luminal secretion of IgA assists in neutralizing exotoxins and microbes. Sampling and presenting of luminal Ags is mediated by specialized M cells 
and dendritic cells, or even by epithelial cells through transcytosis. Gut Ag-presenting cells intrinsically favour the induction of Foxp $3^{+}$Tregs in the gut-draining lymph nodes rather than activating effector $\mathrm{T}$ cells. Further, imprinting of gut-homing receptors (amongst others $\alpha 4 \beta 7$ and CCR9) guaranties the return of these Ag-specific Tregs to the gut [64]. Oral Ag administration makes use of these tolerogenic characteristics to suppress systemic Ag-specific reactivity. The underlying mechanism of oral tolerance induction depends on the dose of $\mathrm{Ag}$ administered, where, at least in preclinical models, low repetitive doses favour the induction of Tregs and high doses favour deletion or anergy of effector T cells [65]. Oral tolerance induction has successfully been applied in experimental autoimmune disease models such as collagen induced arthritis [66] and experimental autoimmune encephalomyelitis $[67,68]$ and relates to the induction of Tregs in these experimental settings [69-71]. Suppressive cytokine production by Tregs (IL4, IL-10 and TGF- $\beta$ ) induces bystander suppression to other (auto-)Ags presented in the close vicinity. This spreading of regulatory responses can even make it redundant to provide the primary Ag, an advantage that can be used in the context of T1D where several auto-Ags are enrolled in the autoimmune cascade and the primary auto- $\mathrm{Ag}$ is not yet unambiguously identified.

Patients would definitely prefer the elegance of this safe and easy way of administration above the inconvenience of parenteral injections. The main challenge faced with oral tolerance induction is to efficiently deliver $\mathrm{Ag}$ doses of superior quality to the intestinal mucosa. Studies unveiled that, unless large quantities are used, intestinal passage causes Ag degradation before it can reach the mucosal immune system of the gut [72,73]. The cost of administering large quantities of high quality Ag being prohibitive makes that there is a strong need for adequate and effective vehicles to control oriented Ag-delivery to the gastrointestinal immune system. Moreover, if such vehicles could also deliver mucosal immune modulators such as IL-10, they could be pivotal in raising tolerogenic immune responses.

\section{L. lactis, a top-notch carrier for tolerance induction}

Along with the concept of using recombinant $L$. lactis for vaccination (recently reviewed [74]) arose the idea of making this host a carrier for tolerance induction (Figure 2). It is indeed not far-fetched thinking to engage an innocuous,

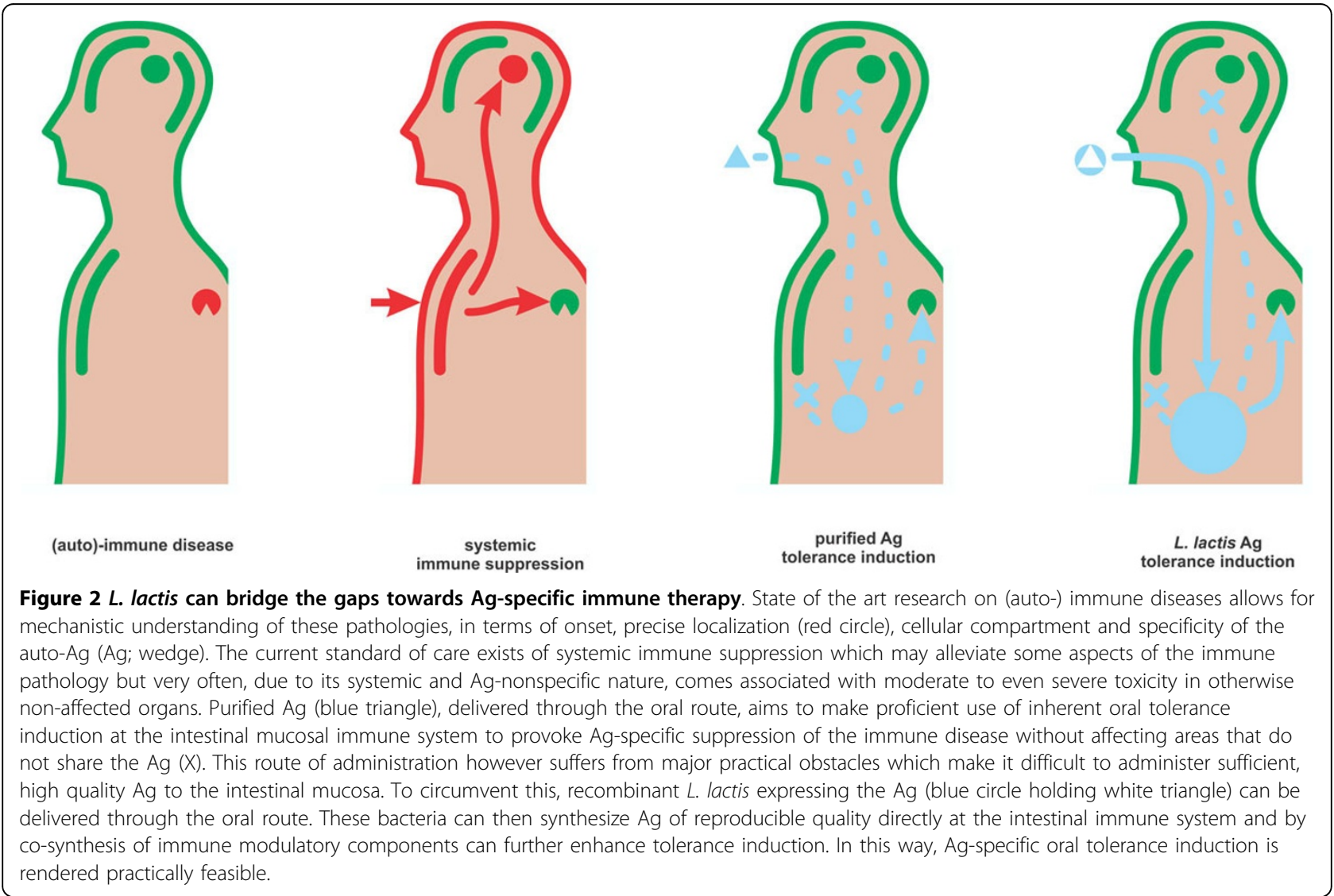


well-known food derived host for dampening rather than stimulating immune reactions.

Initial studies in animals show alleviation of allergic responses subsequent to the administration of recombinant L. lactis. Mucosal - oral or intranasal - administration of recombinant $L$. lactis that secrete bovine beta-lactoglobulin (BLG) leads to the induction of BLG specific fecal IgA [75]. T helper (Th) 1 Th1 cells stimulate cellular rather than humoral immunity and antagonize Th2 cells, which often underlie allergy. Oral application of L. lactis secreting BLG prior to sensitization enhances Th1 response in serum (increased IgG2A, decreased IgE) and ex-vivo splenocytes (increased IFN $\gamma$ ). However, in some settings, splenocytes showed increased interleukin (IL)-5 (Th2). Cellular location of the Ag seems to matter: intracellular BLG seems to drive Th2 response while secreted BLG enhances both Th1 as well as Th2 features, the latter associated with a - less pronounced - IgE induction which is suggestive for reduction of sensitization. On the other hand, IgA, a desired feature for the establishment of tolerance, is induced most prominent in the setting where IgE is not reduced versus the reference [76]. When inoculated intranasal prior to sensitization, recombinant L. lactis producing intracellular major birch pollen allergen BetV1 decrease allergic response to BetV1. Specific serum IgE was decreased and both specific IgG2A and IgG1 are increased. Broncheoalveolar lavages show reduced IL-5 and reduced number of eosinophils, while, both in the airways as well as in the gut, specific IgA was increased [77]. Intranasal inoculation of $L$. lactis producing BLG post sensitization reduced mucosal as well as systemic IgG1 and showed diversion of splenocytes towards Th1 [78]. Taken together, these reports propose the induction of IgA and the avoidance of Th2 response as prominent endpoints and show that - at least to a certain extent - these can be met by use of recombinant L. lactis. The reported synthesis of other known allergens such as peanut allergen Ara h 2 [79] and buckwheat major allergenic storage protein [80] demonstrates that the repertoire of potential immune therapeutic L. lactis is gradually expanding and awaits experimentation.

A limited number of reports demonstrate that tolerance induction through recombinant $L$. lactis can be expanded to auto-Ags. Heat shock proteins (Hsp) form a class of proteins involved in the management of cellular stress and are drivers of inapt immune reactions and their associated pathologies. Bacterial Hsp proteins can provoke cross reactivity to their human counterparts, these then in turn becoming auto-Ags. Oral administration of L. lactis producing Hsp65 shows potential for immune intervention. L. lactis Hsp65 attenuates atherosclerosis in susceptible mice. Both secreted as well as intracellular mycobacterial Hsp65 reduced splenocyte proliferation and atherosclerotic lesions [81]. Further,
L. lactis producing Mycobacterium leprae Hsp65 prevented experimental autoimmune encephalomyelitis in mice by Treg induction [82].

These studies show that, as a carrier for the delivery of immune-pathological epitopes, L. lactis undoubtedly holds promise for anti-allergic and autoimmune therapy: this carrier certainly does not lead to worsening of the autoimmunity or allergy. Caution however should be taken when translating to human medicine. A fundamental aspect of the above mechanisms involves the induction of Th1 responses leading to avoidance of allergic - Th2 - responses. A large portion thereof will evidently be provoked by IFN $\gamma$ production, which in turn may well be a result of the challenge of naive mice with L. lactis, which is not part of its diet and/or the gastrointestinal microflora. Left alone the fact that Th1/ Th2 distinction may not be as clear in humans as it is in mice, nearly no humans are naïve to L. lactis, again due to diet composition. The case may even be more obscure for other bacterial hosts as it will be difficult if not impossible to predict which part of the population has been exposed to any said strain or bioactive component thereof. Novel therapeutic approaches should therefore carry sufficient immune modulatory information, for which exists a rationale that substantiates mouse to human translation, enabling them to act autonomous from primary immune reactions that occur upon naïve encounters.

Many probiotic strains - lactic acid bacteria and other - exert beneficial health effects through surface and secreted proteins, glycoproteins, teichoic acids and lipopolysaccharide. To provoke responses, these molecules interact with pattern recognition receptors of the host [83]. A number of reports show that also L. lactis strains can exert similar immune modulatory effects [78,84-86], amongst others driven by teichoic acids [87], also in conjunction with purified allergen [88]. Again, this shows that $L$. lactis in itself is a good candidate delivery vehicle. However, for the reasons described above, caution should be taken when translating these effects to use in humans. A more rational approach for this type of drug design therefore lies in applying signaling pathways derived from the immune system that have shown to be paralleled in both the experimental animal model as well as in humans. The combination of selected recombinant $\mathrm{Ag}$ and cytokines therefore allows for more predictable steering of pathways for tolerance induction.

The initial findings that cytokines could be delivered to the mucosa through secretion by recombinant $L$. lactis led to the development of a new type of immune modulatory L. lactis [6,7]. Along these lines of thinking, IL-10 secreting L. lactis $[89,90]$ and L. lactis producing IL-12 have been used for anti-allergic therapy [13]. The latter approach provides a good alternative to influence 
Th1/Th2 balance, as shown in ovalbumin-induced asthma [91].

\section{Recombinant $L$. lactis can induce Ag-specific reduction of cellular immunity}

Ag-specific tolerance induction remains the ultimate goal to treat autoimmune and allergic diseases. Oral administration of L. lactis delivering Ags has already demonstrated efficacy by inducing Ag-specific immune suppression. Huibregtse et al. report a detailed mechanism for $\mathrm{T}$ cell-driven Ag-specific tolerance induction by studying oral administration of recombinant $L$. lactis secreting ovalbumin (LLOVA) in a mouse model carrying transgenic OVA-specific $\mathrm{T}$ cell receptors [92]. OVA-sensitized transgenic mice were exposed to oral LL-OVA. Subsequent, OVA-specific tolerance was assessed by delayed-type hypersensitivity measured by ear thickening. L. lactis-mediated intestinal delivery of OVA reduced OVA-specific hypersensitivity in this experimental mouse model. This systemic suppression could not be obtained with purified OVA underlining the added value of $L$. lactis as a mucosal carrier, especially after sensitization. In vitro re-stimulation of the ear-draining lymph nodes, spleen and gut-associated lymph nodes with OVA revealed a higher IL-10 production in the LL-OVA treated animals, suggesting the involvement of a Treg compartment. Further in vitro research showed that LL-OVA feeding suppressed OVA-specific proliferation of $\mathrm{CD} 4^{+}$ splenocytes and this seemed to be effectuated by induced $\mathrm{CD} 4^{+} \mathrm{CD} 25^{-} \mathrm{T}$ cells functioning in a TGF- $\beta$-dependent way. Adoptive transfer of this $\mathrm{CD} 4^{+} \mathrm{CD} 25^{-} \mathrm{T}$ cell compartment suppressed OVA-specific reactivity in OVA-immunized balb/c recipient mice. Taken together, this study was the first to demonstrate efficacy of recombinant L. lactis in inducing Ag-specific Tregs and subsequent Ag-specific tolerance in an experimental mouse model. Moreover it clearly underlines the added value of $L$. lactis mediated delivery over applying purified Ag in mucosal therapy. L. lactis mediated Ag delivery allows for intervention subsequent to sensitization where purified Ag only allows preventive strategies. In addition, the critical amount of OVA required was reduced by several orders of magnitude, which is, as stipulated above, a highly desirable goal.

Can this approach be used to induce Ag-specific reduction of cellular immunity in a host of wild type $\mathrm{T}$ cell repertoire? This appears to be the case indeed, as oral L. lactis secreting the deamidated DQ8 gliadin epitope (one of the drivers of celiac disease) shows a major suppression of intestinal and systemic DQ8-restricted T cell responses in NOD AB ${ }^{\circ} \mathrm{DQ} 8$ transgenic mice [93].

\section{L. lactis: the gateway towards a novel, Ag-specific T1D therapy}

Also in the context of autoimmunity, oral administration of recombinant L. lactis that secrete auto-Ags shows to be a valid approach to restore tolerance. A new therapeutic strategy for T1D was devised by use of recombinant $L$. lactis secreting human pro-insulin (PINS) and IL-10 (LL-PINS+IL-10) to recently-diagnosed diabetic NOD mice [94]. A combination therapy (CT) of LL-PINS+IL-10 with a short-course of subtherapeutic doses anti-CD3 Abs reversed diabetes in 59\% of treated mice in comparison to $25 \%$ with anti-CD3 monotherapy and 15\% when using LL-PINS+IL-10 alone. Moreover anti-CD3 plus LL-PINS reversed diabetes in $49 \%$ of treated mice highlighting the importance of mucosal co-delivery of IL-10 and Ag. This observation underlines the great potential of combination strategies: systemic immunomodulation is combined with Ag-specificity, thereby providing specificity and increasing efficacy. As such, toxic dosages of systemic immunomodulators can be reduced to non-harmful - but as such sub-therapeutic - levels.

Successful CT was associated with preservation of remaining $\beta$-cell mass, not with increased proliferation or generation of new $\beta$-cells. Moreover, cured CT-treated animals showed increased frequencies of $\mathrm{CD} 4{ }^{+} \mathrm{CD} 25$ ${ }^{+}$Foxp $3^{+}$Tregs in pancreatic-draining lymph nodes. These Tregs exhibited polyclonal and Ag-specific suppressive capacity in vitro in addition to disease-specific suppressive capacity in vivo. Also, locally in the pancreas, increased frequencies of proliferating Foxp $3^{+}$Tregs could be detected, further suggesting that CT of low-dose antiCD3 with LL-PINS+IL-10 induces PINS-specific Tregs that migrate to the site of inflammation and inhibit further $\beta$-cell destruction.

To verify whether other auto-Ags can induce or enhance diabetes remission, recombinant $\mathrm{L}$. lactis secreting T1D-related auto-Ag GAD65 have been tested successfully in a similar setting [95]. Interestingly, LL-GAD CT retained a similar $60 \%$ diabetes remission even in severely hyperglycemic (late) NOD mice as opposed to LL-PINS+IL-10 CT. This could be explained by the hypothesized primary role for PINS in the autoimmune cascade followed by GAD65 reactivity and suggests that LL-GAD CT is more widely applicable and can be used in more advanced stages of T1D.

\section{Bringing recombinant $L$. lactis to the clinic}

Moving recombinant $L$. lactis forward to clinical experimentation is the next step in achieving the ultimate goal: the development of a novel pharmaceutical product. Key aspects encompass clear and unambiguous genetic engineering, undisputable safety profile and high quality chemistry, manufacturing and controls (CMC). The whole of these will be at the center of the authorities' scrutiny and precise approach will lay the foundation for regulatory approval.

The regulatory approval process to use live recombinant bacteria as drugs faces unique challenges. First, 
research and production operations need to be elevated to the standard of the pharmaceutical industry. According to guidelines from "International Conference on Harmonization of Technical Requirements for Registration of Pharmaceuticals for Human Use" (ICH), production of pharmaceuticals must comply with good manufacturing practice (GMP). Product quality and consistency needs to be demonstrated, including testing of identity, purity, potency and stability. Animal toxicology studies must demonstrate the safety of the drug product before it can be administered to humans. Second, drugs that are deliberately releasing recombinant organisms need to follow special guidelines addressing environmental containment and eradication. As an inherent part of communication towards society of its know-how on environmental safety, the clinical trial sponsor will need to demonstrate appropriate risk assessment and must avail of a superbly functioning containment system [96].

The bacterial organism of choice is by absolute preference well described and with a long standing history of safe use in humans. For this it should have very few if any case records in medical literature. Growth of the host should be susceptible to a panorama of antibiotics but it may be an advantage if a certain number of those will still allow for Ag expression. Residence of the organism inside the host - whether transient, lingering or capable of active colonization - will be determining the degree to which a handle on dosage and timing will exist, both key aspects of a clear pharmacodynamic profile. From this point of view, L. lactis has a clear advantage over other hosts. It is a well described, non-colonizing species, with an excellent track-record of safe use in humans. More specific, as described in detail above, many groups showed safety in tolerance induction in that recombinant L. lactis abstain of any aggravation of the studied (auto-) immune pathologies. Further, L. lactis is susceptible to a range of antibiotics that prevent growth but not recombinant protein expression.

Genetic engineering must be robust and should preclude the use of plasmids and other mobile elements and should be free of antibiotic selection markers. This makes the bacterial chromosome, at sites away from transposons and IS elements, the desired carrier for Ag gene expression. The genetic engineering must ensure environmental containment, eventually by a combination of inherent features of the species and by recombinant traits [96].

Following demonstration of biological activity in animals, drug development - also when starting from a recombinant bacterium - follows set rules. As for any pharmaceutical, establishing a medicinal product requires the set-up of adequate CMC. The process of genetic engineering, strain selection and maintenance of a research cell bank is straightforward and well known to most researchers in the field. These activities are - almost by definition -non-GMP processes. Documentation must nevertheless be of the highest quality because at this stage, identity of the active component is fixed and stability of the transgenic trait and containment system must be demonstrated. Every activity beyond the final strain selection - the establishment of a master cell bank, the development of the processes for fermentation and biomass concentration as well as lyophilization to produce a drug substance in bulk and stability studies - need to comply with GMP standards and documentation should be recorded accordingly. All segments of the production process must be robust - i.e. should not overly depend on any variable - and scalable. All raw materials have to be of clinical grade and by high preference, if not exclusively, free of all animal-derived products. The product must be safe and therefore the very initial development phase will encompass toxicology studies in relevant animal species and small, phase I safety and tolerability studies in humans. The drug must be sufficiently stable to allow treatment of thousands of patients. At any of the relevant stages during processing, thorough and reliable, validated documentation is required.

Approval or rejection of an application to perform a clinical trial resides with national or European agencies. Initially, all regulatory systems afford drug developers a certain period of scientific advice during which they can be approached to discuss future steps of product development. Such a consultancy phase allows the listing of supporting studies the agencies consider necessary, including additional animal proof of concept and safety studies. Without this window of initial communication before the filing of the final product, a late discovery of gaps in the data in a more advanced phase could derail an entire project.

Although all clinical trial applications require data on animal pharmacology and toxicology, manufacturing information, clinical protocols and investigator information, regulatory agencies in different countries may have unique requirements which need to be taken into account when setting up a dossier. When comparing Europe vs. North America the contents of the application may vary substantially, mainly differing in whether all or part of the existing documentation must be included. U.S. authorities (U.S. Food and Drug Administration; FDA) require having all of the documentation in the file. European authorities (European Medicines Agency; EMA) request an overview on strategy and a product description, but supporting data remain at the sponsor, eventually to be presented upon request. Canadian authorities (Health Canada) have very concise regulations, and will request all documentation to be kept at the study sites, again to be presented upon request. Where most authorities will require clinical trial 
applications (CTA) per specific trial; U.S. FDA utilizes the "open" investigational new drug (IND) process. The IND is product specific and the sponsor continues to submit new data along the road towards market approval.

Any clinical trial involving recombinant organisms will be categorized as "contained use" or "deliberate release", the first requiring absolute physical containment, the latter harmonizing the use of the recombinant organism and its release in the environment. For most authorities the application for contained use - provided physical containment is absolute, which is left at the discretion of the sponsor - is relatively straightforward. Medical use however is almost inherently coupled to deliberate release of the recombinant organisms in the environment. Regulations on the deliberate release of recombinant organisms differ between countries, and the application process involves differing steps. The U.S. system sets in place the NIH Recombinant DNA Advisory Committee (RAC) to advise local authorities in their decisions when overseeing a clinical trial application involving recombinant organisms. Decisions on the use of recombinant organisms however remain with the clinical centers. Canadian and European authorities will decide on the use of recombinant organisms on a national level. Canadian authorities apply no guidelines on the use of recombinant organisms. The Canadian environmental protection agency however will judge any novel product - regardless of its origin - to be entered into Canada on its potential environmental impact upon "deliberate" release. The "new substance notification" application undergoes thorough scrutiny, in the specific case of recombinant microflora on data to demonstrate the effectiveness of the containment system and experiments and literature that allow judgment on environmental impact. Specific for the European review and approval process is the scrutiny for products involving recombinant DNA, which is regarded as fundamentally different from conventional approaches.

The above, complex path is essential to guarantee safety to humans. When entering into human tolerance induction therapy, this path is however not expected to differ extensively from that of earlier clinical trials with recombinant $L$. lactis that have been conducted successfully (http://ClinicalTrials.gov Identifiers NCT00729872 and NCT00938080 [15]). Therefore, the conduct of clinical trials using recombinant $L$. lactis for Ag-specific tolerance induction has moved beyond the visionary to become practicable.

\section{Conclusion: L. lactis can bridge the gaps towards Ag-specific immune therapy}

Immune diseases driven by innocuous - auto or allo Ags are rapidly emerging. As judged from their global evolution, this phenomenon goes along with western lifestyle $[97,98]$. The manifestations of these diseases come in a wide variety, from "unpleasant" to "life threatening when left untreated". Despite our growing mechanistic understanding, the current standard of care remains unsatisfactory in many cases. Shortcomings range from partial and temporal relief to being associated with highly undesirable, widespread toxic side effects. It will be necessary to harness our molecular immunological understanding in order to develop medication that can reach the suitable outcome: Ag-specific tolerance induction devoid of side effects. Oral tolerance, a system that manages the discrimination between friend and foe in the intestine, is one possible entry into this field. However it remains largely untapped because of practical and technological hurdles. In prophylactic settings, clear demonstration of Ag-specific oral tolerance induction has been given in experimental animals. It however remains very difficult to deliver sufficient amounts of high quality Ag to the human intestine. Rather than being merely preventive, L. lactis Ag-delivery has shown suitable to support intervention strategies in Ag-driven immune diseases. With recombinant $L$. lactis we avail of the technological tools to bridge between our molecular understanding and the practicalities of human medicine. We can engineer L. lactis to produce (auto-) Ags and immune modulatory factors and genetic engineering is such that it is safe to use. Large scale GMP manufacturing has been established and quality controls, both critical components for clinical experimentation under ICH guidelines, are in place. All this has been shown necessary and sufficiently elaborated to allow successful completion of the regulatory approval process. We now find ourselves at a pivotal point: we have the tools and experience to allow recombinant $L$. lactis to make a difference in healthcare by helping out people suffering from prominent but largely unmet medical needs.

\section{Competing interests}

L.S. is co-founder, shareholder and employee of ActoGeniX NV.

\section{Acknowledgements}

S.R. is holder of a Baekeland fellowship from the Agency for Innovation by Science and Technology in Flanders (IWT-90702). The authors wish to thank Dr. Pieter Rottiers and Dr. Conny Gysemans for their much valued discussion and careful reading of the manuscript.

\section{Declarations}

This article has been published as part of Microbial Cell Factories Volume 13 Supplement 1, 2014: Proceedings of the 11 th International Symposium on Lactic Acid Bacteria. The full contents of the supplement are available online at http://www.microbialcellfactories.com/supplements/13/S1. Publication charges for this supplement were funded by the Stichting Symposium on Lactic Acid Bacteria. The articles have undergone the journal's standard peer review process for supplements. EJ is employed by Chr Hansen A/S, is a shareholder in Chr Hansen A/S; and has applied for patents relating to the content of an article which he did not edit but which forms part of this supplement. MK is an employee of Nizo. The other Supplement Editors declare that they have no competing interests. 


\section{Authors' details}

${ }^{1}$ Clinical and Experimental Endocrinology (CEE), KU Leuven, 3000, Leuven, Belgium. ${ }^{2}$ ActoGeniX NV, 9052, Zwijnaarde, Belgium.

Published: 29 August 2014

\section{References}

1. Miller FW, Alfredsson L, Costenbader KH, Kamen DL, Nelson LM, Norris JM, De Roos AJ: Epidemiology of environmental exposures and human autoimmune diseases: findings from a National Institute of Environmental Health Sciences Expert Panel Workshop. Journal of autoimmunity 2012, 39:259-271.

2. Carter $\mathrm{PH}$, Zhao Q: Clinically validated approaches to the treatment of autoimmune diseases. Expert opinion on investigational drugs 2010, 19:195-213.

3. Worldwide variation in prevalence of symptoms of asthma, allergic rhinoconjunctivitis, and atopic eczema: ISAAC. The International Study of Asthma and Allergies in Childhood (ISAAC) Steering Committee. Lancet 1998, 351:1225-1232

4. Romagnani S: The increased prevalence of allergy and the hygiene hypothesis: missing immune deviation, reduced immune suppression, or both? Immunology 2004, 112:352-363.

5. Asher MI, Montefort S, Bjorksten B, Lai CK, Strachan DP, Weiland SK, Williams $\mathrm{H}$, Group IPTS: Worldwide time trends in the prevalence of symptoms of asthma, allergic rhinoconjunctivitis, and eczema in childhood: ISAAC Phases One and Three repeat multicountry crosssectional surveys. Lancet 2006, 368:733-743.

6. Steidler L, Hans W, Schotte L, Neirynck S, Obermeier F, Falk W, Fiers W, Remaut E: Treatment of murine colitis by Lactococcus lactis secreting interleukin-10. Science 2000, 289:1352-1355.

7. Steidler L, Robinson K, Chamberlain L, Schofield KM, Remaut E, Le Page RW, Wells JM: Mucosal delivery of murine interleukin-2 (IL-2) and IL-6 by recombinant strains of Lactococcus lactis coexpressing antigen and cytokine. Infect Immun 1998, 66:3183-3189.

8. Steidler L, Wells JM, Raeymaekers A, Vandekerckhove J, Fiers W, Remaut E: Secretion of biologically active murine interleukin-2 by Lactococcus lactis subsp. lactis. Applied and Environmental Microbiology 1995, 61:1627-1629.

9. Vandenbroucke $\mathrm{K}$, de Haard H, Beirnaert E, Dreier T, Lauwereys M, Huyck L, Van Huysse J, Demetter P, Steidler L, Remaut E, et al: Orally administered L. lactis secreting an anti-TNF Nanobody demonstrate efficacy in chronic colitis. Mucosal immunology 2010, 3:49-56.

10. Vandenbroucke K, Hans W, Van Huysse J, Neirynck S, Demetter P, Remaut E, Rottiers $P$, Steidler $L$ : Active delivery of trefoil factors by genetically modified Lactococcus lactis prevents and heals acute colitis in mice. Gastroenterology 2004, 127:502-513.

11. Bermudez-Humaran LG, Langella P, Cortes-Perez NG, Gruss A, TamezGuerra RS, Oliveira SC, Saucedo-Cardenas O, Montes de Oca-Luna R, Le Loir Y: Intranasal immunization with recombinant Lactococcus lactis secreting murine interleukin-12 enhances antigen-specific Th1 cytokine production. Infect Immun 2003, 71:1887-1896.

12. Bermudez-Humaran LG, Nouaille S, Zilberfarb V, Corthier G, Gruss A, Langella P, Issad T: Effects of intranasal administration of a leptinsecreting Lactococcus lactis recombinant on food intake body weight, and immune response of mice. Applied and Environmental Microbiology 2007, 73:5300-5307.

13. Cortes-Perez NG, Ah-Leung S, Bermudez-Humaran LG, Corthier G, Wal JM, Langella P, Adel-Patient K: Intranasal coadministration of live lactococci producing interleukin-12 and a major cow's milk allergen inhibits allergic reaction in mice. Clinical and vaccine immunology : CVI 2007, 14:226-233.

14. Motta JP, Bermudez-Humaran LG, Deraison C, Martin L, Rolland C, Rousset P, Boue J, Dietrich G, Chapman K, Kharrat P, et al: Food-grade bacteria expressing elafin protect against inflammation and restore colon homeostasis. Science translational medicine 2012, 4:158ra144.

15. Limaye SA, Haddad RI, Cilli F, Sonis ST, Colevas AD, Brennan MT, Hu KS, Murphy BA: Phase 1b, multicenter, single blinded, placebo-controlled, sequential dose escalation study to assess the safety and tolerability of topically applied AG013 in subjects with locally advanced head and neck cancer receiving induction chemotherapy. Cancer 2013, 119:4268-4276.
16. Patterson CC, Dahlquist GG, Gyurus E, Green A, Soltesz G, Group ES: Incidence trends for childhood type 1 diabetes in Europe during 1989-2003 and predicted new cases 2005-20: a multicentre prospective registration study. Lancet 2009, 373:2027-2033.

17. Bresson D, Togher L, Rodrigo E, Chen Y, Bluestone JA, Herold KC, von Herrath M: Anti-CD3 and nasal proinsulin combination therapy enhances remission from recent-onset autoimmune diabetes by inducing Tregs. J Clin Invest 2006, 116:1371-1381.

18. Bluestone JA, Herold K, Eisenbarth G: Genetics, pathogenesis and clinical interventions in type 1 diabetes. Nature 2010, 464:1293-1300.

19. Knip M, Siljander $\mathrm{H}$ : Autoimmune mechanisms in type 1 diabetes. Autoimmun Rev 2008, 7:550-557.

20. Haskins $\mathrm{K}$, Cooke A: CD4 T cells and their antigens in the pathogenesis of autoimmune diabetes. Current opinion in immunology 2011, 23:739-745.

21. Tedesco D, Haragsim L: Cyclosporine: a review. Journal of transplantation 2012, 2012:230386.

22. Cyclosporin-induced remission of IDDM after early intervention. Association of $1 \mathrm{yr}$ of cyclosporin treatment with enhanced insulin secretion. The Canadian-European Randomized Control Trial Group. Diabetes 1988, 37:1574-1582.

23. Feutren G, Papoz L, Assan R, Vialettes B, Karsenty G, Vexiau P, Du Rostu H, Rodier M, Sirmai J, Lallemand A, et al.: Cyclosporin increases the rate and length of remissions in insulin-dependent diabetes of recent onset. Results of a multicentre double-blind trial. Lancet 1986, 2:119-124.

24. Dupre J, Stiller CR, Gent M, Donner A, von Graffenreid B, Murphy G, Heinrichs D, Jenner MR, Keown PA, Laupacis A, et al.: Effects of immunosuppression with cyclosporine in insulin-dependent diabetes mellitus of recent onset: the Canadian open study at 44 months. Transplantation proceedings 1988, 20:184-192.

25. Martin S, Schernthaner G, Nerup J, Gries FA, Koivisto VA, Dupre J, Standl E, Hamet P, McArthur R, Tan MH, et al.: Follow-up of cyclosporin A treatment in type 1 (insulin-dependent) diabetes mellitus: lack of longterm effects. Diabetologia 1991, 34:429-434.

26. Bougneres PF, Landais P, Boisson C, Carel JC, Frament N, Boitard C, Chaussain JL, Bach JF: Limited duration of remission of insulin dependency in children with recent overt type I diabetes treated with low-dose cyclosporin. Diabetes 1990, 39:1264-1272.

27. Parving HH, Tarnow L, Nielsen FS, Rossing P, Mandrup-Poulsen T, Osterby R, Nerup J: Cyclosporine nephrotoxicity in type 1 diabetic patients. A 7-year follow-up study. Diabetes Care 1999, 22:478-483.

28. Penaranda C, Tang Q, Bluestone JA: Anti-CD3 therapy promotes tolerance by selectively depleting pathogenic cells while preserving regulatory T cells. J Immunol 2011, 187:2015-2022.

29. Chatenoud L, Baudrihaye MF, Kreis H, Goldstein G, Schindler J, Bach JF: Human in vivo antigenic modulation induced by the anti-T cell OKT3 monoclonal antibody. Eur J Immunol 1982, 12:979-982.

30. Nishio J, Feuerer M, Wong J, Mathis D, Benoist C: Anti-CD3 therapy permits regulatory $T$ cells to surmount $T$ cell receptor-specified peripheral niche constraints. The Journal of experimental medicine 2010, 207:1879-1889.

31. Belghith M, Bluestone JA, Barriot S, Megret J, Bach JF, Chatenoud L: TGFbeta-dependent mechanisms mediate restoration of self-tolerance induced by antibodies to CD3 in overt autoimmune diabetes. Nature Medicine 2003, 9:1202-1208.

32. Chatenoud L, Thervet E, Primo J, Bach JF: Anti-CD3 antibody induces longterm remission of overt autoimmunity in nonobese diabetic mice. Proc Natl Acad Sci USA 1994, 91:123-127.

33. Chatenoud L, Primo J, Bach JF: CD3 antibody-induced dominant self tolerance in overtly diabetic NOD mice. J Immunol 1997, 158:2947-2954.

34. Xu D, Alegre ML, Varga SS, Rothermel AL, Collins AM, Pulito VL, Hanna LS, Dolan KP, Parren PW, Bluestone JA, et al: In vitro characterization of five humanized OKT3 effector function variant antibodies. Cellular immunology 2000, 200:16-26.

35. Bolt S, Routledge E, Lloyd I, Chatenoud L, Pope H, Gorman SD, Clark M, Waldmann $\mathrm{H}$ : The generation of a humanized, non-mitogenic CD3 monoclonal antibody which retains in vitro immunosuppressive properties. Eur J Immunol 1993, 23:403-411.

36. Herold KC, Hagopian W, Auger JA, Poumian-Ruiz E, Taylor L, Donaldson D, Gitelman SE, Harlan DM, Xu D, Zivin RA, Bluestone JA: Anti-CD3 monoclonal antibody in new-onset type 1 diabetes mellitus. $N$ Engl $J$ Med 2002, 346:1692-1698. 
37. Herold KC, Gitelman SE, Masharani U, Hagopian W, Bisikirska B, Donaldson D, Rother K, Diamond B, Harlan DM, Bluestone JA: A single course of anti-CD3 monoclonal antibody hOKT3gamma1(Ala-Ala) results in improvement in C-peptide responses and clinical parameters for at least 2 years after onset of type 1 diabetes. Diabetes 2005, 54:1763-1769.

38. Keymeulen B, Vandemeulebroucke E, Ziegler AG, Mathieu C, Kaufman L, Hale G, Gorus F, Goldman M, Walter M, Candon S, et al: Insulin needs after CD3-antibody therapy in new-onset type 1 diabetes. N Engl J Med 2005, 352:2598-2608

39. Keymeulen B, Walter M, Mathieu C, Kaufman L, Gorus F, Hilbrands R, Vandemeulebroucke E, Van de Velde U, Crenier L, De Block C, et al: Fouryear metabolic outcome of a randomised controlled CD3-antibody trial in recent-onset type 1 diabetic patients depends on their age and baseline residual beta cell mass. Diabetologia 2010, 53:614-623.

40. Herold KC, Gitelman S, Greenbaum C, Puck J, Hagopian W, Gottlieb P, Sayre $P$, Bianchine $P$, Wong E, Seyfert-Margolis $V$, et al: Treatment of patients with new onset Type 1 diabetes with a single course of antiCD3 mAb Teplizumab preserves insulin production for up to 5 years. Clinical immunology (Orlando, Fla 2009, 132:166-173.

41. Ambery P, Donner TW, Biswas N, Donaldson J, Parkin J, Dayan CM: Efficacy and safety of low-dose otelixizumab anti-CD3 monoclonal antibody in preserving C-peptide secretion in adolescent type 1 diabetes: DEFEND-2, a randomized, placebo-controlled, double-blind, multi-centre study. Diabetic medicine : a journal of the British Diabetic Association 2013.

42. Sherry N, Hagopian W, Ludvigsson J, Jain SM, Wahlen J, Ferry RJ, Bode B, Aronoff S, Holland C, Carlin D, et al: Teplizumab for treatment of type 1 diabetes (Protege study): 1-year results from a randomised, placebocontrolled trial. Lancet 2011, 378:487-497.

43. Hagopian W, Ferry RJ, Sherry N, Carlin D, Bonvini E, Johnson S, Stein KE, Koenig S, Daifotis AG, Herold KC, et al: Teplizumab preserves C-peptide in recent-onset type 1 diabetes: two-year results from the randomized, placebo-controlled Protege trial. Diabetes 2013, 62:3901-3908.

44. Herold KC, Gitelman SE, Ehlers MR, Gottlieb PA, Greenbaum CJ, Hagopian W, Boyle KD, Keyes-Elstein L, Aggarwal S, Phippard D, et al: Teplizumab (anti-CD3 mAb) treatment preserves C-peptide responses in patients with new-onset type 1 diabetes in a randomized controlled trial: metabolic and immunologic features at baseline identify a subgroup of responders. Diabetes 2013, 62:3766-3774.

45. Jiang HR, Taylor N, Duncan L, Dick AD, Forrester JV: Total dose and frequency of administration critically affect success of nasal mucosal tolerance induction. The British journal of ophthalmology 2001, 85:739-744.

46. Brewer JM: (How) do aluminium adjuvants work? Immunol Lett 2006, 102:10-15

47. HogenEsch $\mathrm{H}$ : Mechanisms of stimulation of the immune response by aluminum adjuvants. Vaccine 2002, 20(Suppl 3):S34-39.

48. Baekkeskov S, Aanstoot HJ, Christgau S, Reetz A, Solimena M, Cascalho M, Folli F, Richter-Olesen $\mathrm{H}$, De Camilli P: Identification of the $64 \mathrm{~K}$ autoantigen in insulin-dependent diabetes as the GABA-synthesizing enzyme glutamic acid decarboxylase. Nature 1990, 347:151-156.

49. Payton MA, Hawkes CJ, Christie MR: Relationship of the 37,000- and 40,000-M(r) tryptic fragments of islet antigens in insulin-dependent diabetes to the protein tyrosine phosphatase-like molecule IA-2 (ICA512). J Clin Invest 1995, 96:1506-1511.

50. Di Lorenzo TP, Peakman M, Roep BO: Translational mini-review series on type 1 diabetes: Systematic analysis of $T$ cell epitopes in autoimmune diabetes. Clin Exp Immunol 2007, 148:1-16.

51. Daniel D, Wegmann DR: Protection of nonobese diabetic mice from diabetes by intranasal or subcutaneous administration of insulin peptide B-(9-23). Proc Natl Acad Sci USA 1996, 93:956-960.

52. Maron R, Guerau-de-Arellano M, Zhang $X$, Weiner HL: Oral administration of insulin to neonates suppresses spontaneous and cyclophosphamide induced diabetes in the NOD mouse. Journal of autoimmunity 2001, 16:21-28.

53. Pleau JM, Fernandez-Saravia F, Esling A, Homo-Delarche F, Dardenne M: Prevention of autoimmune diabetes in nonobese diabetic female mice by treatment with recombinant glutamic acid decarboxylase (GAD 65). Clinical immunology and immunopathology 1995, 76:90-95.

54. Tian J, Atkinson MA, Clare-Salzler M, Herschenfeld A, Forsthuber T, Lehmann PV, Kaufman DL: Nasal administration of glutamate decarboxylase (GAD65) peptides induces Th2 responses and prevents murine insulin-dependent diabetes. The Journal of experimental medicine 1996, 183:1561-1567.
55. Guan Y, Zhang M, Li Y, Cao W, Ji M, Liu Y: Vaccination with IA-2 autoantigen can prevent late prediabetic nonobese diabetic mice from developing diabetes mellitus. Diabetes research and clinical practice 2012, 95:93-97.

56. Cetkovic-Cvrlje M, Gerling IC, Muir A, Atkinson MA, Elliott JF, Leiter EH: Retardation or acceleration of diabetes in NOD/Lt mice mediated by intrathymic administration of candidate beta-cell antigens. Diabetes 1997, 46:1975-1982.

57. Diabetes Prevention Trial-Type 1 Diabetes Study G: Effects of insulin in relatives of patients with type 1 diabetes mellitus. N Engl J Med 2002, 346:1685-1691.

58. Vandemeulebroucke E, Gorus FK, Decochez K, Weets I, Keymeulen B, De Block C, Tits J, Pipeleers DG, Mathieu C, Belgian Diabetes R: Insulin treatment in IA-2A-positive relatives of type 1 diabetic patients. Diabetes \& metabolism 2009, 35:319-327.

59. Nanto-Salonen K, Kupila A, Simell S, Siljander H, Salonsaari T, Hekkala A, Korhonen S, Erkkola R, Sipila Jl, Haavisto L, et al: Nasal insulin to prevent type 1 diabetes in children with HLA genotypes and autoantibodies conferring increased risk of disease: a double-blind, randomised controlled trial. Lancet 2008, 372:1746-1755.

60. Skyler JS, Krischer JP, Wolfsdorf J, Cowie C, Palmer JP, Greenbaum C Cuthbertson D, Rafkin-Mervis LE, Chase HP, Leschek E: Effects of oral insulin in relatives of patients with type 1 diabetes: The Diabetes Prevention Trial-Type 1. Diabetes Care 2005, 28:1068-1076.

61. Ludvigsson J, Krisky D, Casas R, Battelino T, Castano L, Greening J, Kordonouri O, Otonkoski T, Pozzilli P, Robert JJ, et al: GAD65 antigen therapy in recently diagnosed type 1 diabetes mellitus. $N$ Engl J Med 2012, 366:433-442.

62. Agardh CD, Lynch KF, Palmer M, Link K, Lernmark A: GAD65 vaccination: 5 years of follow-up in a randomised dose-escalating study in adult-onset autoimmune diabetes. Diabetologia 2009, 52:1363-1368.

63. Weiner HL, da Cunha AP, Quintana F, Wu H: Oral tolerance. Immunol Rev 2011, 241:241-259

64. Cassani B, Villablanca EJ, Quintana FJ, Love PE, Lacy-Hulbert A, Blaner WS, Sparwasser T, Snapper SB, Weiner HL, Mora JR: Gut-tropic T cells that express integrin alpha4beta7 and CCR9 are required for induction of oral immune tolerance in mice. Gastroenterology 2011, 141:2109-2118.

65. Mayer L, Shao L: Therapeutic potential of oral tolerance. Nature Review Immunology 2004, 4:407-419.

66. Nagler-Anderson C, Bober LA, Robinson ME, Siskind GW, Thorbecke GJ: Suppression of type II collagen-induced arthritis by intragastric administration of soluble type II collagen. Proc Natl Acad Sci USA 1986, 83:7443-7446.

67. Higgins PJ, Weiner HL: Suppression of experimental autoimmune encephalomyelitis by oral administration of myelin basic protein and its fragments. J Immunol 1988, 140:440-445.

68. Bitar DM, Whitacre CC: Suppression of experimental autoimmune encephalomyelitis by the oral administration of myelin basic protein. Cellular immunology 1988, 112:364-370.

69. Garcia G, Komagata Y, Slavin AJ, Maron R, Weiner HL: Suppression of collagen-induced arthritis by oral or nasal administration of type II collagen. Journal of autoimmunity 1999, 13:315-324.

70. Chen Y, Inobe J, Kuchroo VK, Baron JL, Janeway CA, Weiner HL: Oral tolerance in myelin basic protein T-cell receptor transgenic mice: suppression of autoimmune encephalomyelitis and dose-dependent induction of regulatory cells. Proc Natl Acad Sci USA 1996, 93:388-391.

71. Santos $L M$, al-Sabbagh A, Londono A, Weiner $H L$ : Oral tolerance to myelin basic protein induces regulatory TGF-beta-secreting T cells in Peyer's patches of SJL mice. Cellular immunology 1994, 157:439-447.

72. Bruce MG, Ferguson A: The influence of intestinal processing on the immunogenicity and molecular size of absorbed, circulating ovalbumin in mice. Immunology 1986, 59:295-300.

73. Bruce $M G$, Ferguson A: Oral tolerance to ovalbumin in mice: studies of chemically modified and 'biologically filtered' antigen. Immunology 1986, 57:627-630.

74. Bahey-El-Din M: Lactococcus lactis-based vaccines from laboratory bench to human use: an overview. Vaccine 2012, 30:685-690.

75. Chatel JM, Langella P, Adel-Patient K, Commissaire J, Wal JM, Corthier G: Induction of mucosal immune response after intranasal or oral inoculation of mice with Lactococcus lactis producing bovine betalactoglobulin. Clinical and diagnostic laboratory immunology 2001, 8:545-551 
76. Adel-Patient K, Ah-Leung S, Creminon C, Nouaille S, Chatel JM, Langella P, Wal JM: Oral administration of recombinant Lactococcus lactis expressing bovine beta-lactoglobulin partially prevents mice from sensitization. Clin Exp Allergy 2005, 35:539-546.

77. Daniel C, Repa A, Wild C, Pollak A, Pot B, Breiteneder H, Wiedermann U, Mercenier $A$ : Modulation of allergic immune responses by mucosal application of recombinant lactic acid bacteria producing the major birch pollen allergen Bet v 1. Allergy 2006, 61:812-819.

78. Cortes-Perez NG, Ah-Leung S, Bermudez-Humaran LG, Corthier G, Langella P, Wal JM, Adel-Patient K: Allergy therapy by intranasal administration with recombinant Lactococcus lactis Producing bovine beta-lactoglobulin. International archives of allergy and immunology 2009, 150:25-31.

79. Glenting J, Poulsen LK, Kato K, Madsen SM, Frokiaer H, Wendt C, Sorensen HW: Production of Recombinant Peanut Allergen Ara h 2 using Lactococcus lactis. Microb Cell Fact 2007, 6:28.

80. Shigemori S, Yonekura S, Sato T, Otani H, Shimosato T: Expression of the immunoreactive buckwheat major allergenic storage protein in Lactococcus lactis. Applied microbiology and biotechnology 2013, 97:3603-3611.

81. Jing $H$, Yong $L$, Haiyan $L$, Yanjun $M, Y u n ~ X, ~ Y u ~ Z$, Taiming $L$, Rongyue $C$, Liang J, Jie W, et al: Oral administration of Lactococcus lactis delivered heat shock protein 65 attenuates atherosclerosis in low-density lipoprotein receptor-deficient mice. Vaccine 2011, 29:4102-4109.

82. Rezende RM, Oliveira RP, Medeiros SR, Gomes-Santos AC, Alves AC, Loli FG, Guimaraes MA, Amaral SS, da Cunha AP, Weiner HL, et al: Hsp65-producing Lactococcus lactis prevents experimental autoimmune encephalomyelitis in mice by inducing CD4+LAP+ regulatory $\mathrm{T}$ cells. Journal of autoimmunity 2013, 40:45-57.

83. Lebeer S, Vanderleyden J, De Keersmaecker SC: Host interactions of probiotic bacterial surface molecules: comparison with commensals and pathogens. Nature reviews 2010, 8:171-184.

84. Zuercher AW, Weiss M, Holvoet S, Moser M, Moussu H, van Overtvelt L, Horiot S, Moingeon P, Nutten S, Prioult G, et al: Lactococcus lactis NCC 2287 alleviates food allergic manifestations in sensitized mice by reducing IL-13 expression specifically in the ileum. Clinical \& developmental immunology 2012, 2012:485750.

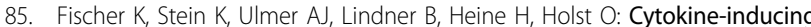
lipoteichoic acids of the allergy-protective bacterium Lactococcus lactis G121 do not activate via Toll-like receptor 2. Glycobiology 2011, 21:1588-1595.

86. Rupa P, Schmied J, Wilkie BN: Prophylaxis of experimentally induced ovomucoid allergy in neonatal pigs using Lactococcus lactis. Veterinary immunology and immunopathology 2011, 140:23-29.

87. Fischer $K$, Vinogradov $E_{\text {, Lindner } B}$, Heine $H$, Holst $O$ : The structure of the extracellular teichoic acids from the allergy-protective bacterium Lactococcus lactis G121. Biological chemistry 2012, 393:749-755.

88. Repa A, Grangette C, Daniel C, Hochreiter R, Hoffmann-Sommergruber K, Thalhamer J, Kraft D, Breiteneder H, Mercenier A, Wiedermann U: Mucosal co-application of lactic acid bacteria and allergen induces counterregulatory immune responses in a murine model of birch pollen allergy. Vaccine 2003, 22:87-95

89. Marinho FA, Pacifico LG, Miyoshi A, Azevedo V, Le Loir Y, Guimaraes VD, Langella P, Cassali GD, Fonseca CT, Oliveira SC: An intranasal administration of Lactococcus lactis strains expressing recombinant interleukin-10 modulates acute allergic airway inflammation in a murine model. Clin Exp Allergy 2010, 40:1541-1551.

90. Frossard CP, Steidler L, Eigenmann PA: Oral administration of an IL-10secreting Lactococcus lactis strain prevents food-induced $\lg \mathrm{E}$ sensitization. The Journal of allergy and clinical immunology 2007, 119:952-959.

91. Wu C, Yang G, Bermudez-Humaran LG, Pang Q, Zeng Y, Wang J, Gao X: International immunopharmacology 2006, 6:610-615.

92. Huibregtse IL, Snoeck V, de Creus A, Braat H, De Jong EC, Van Deventer SJ, Rottiers P: Induction of ovalbumin-specific tolerance by oral administration of Lactococcus lactis secreting ovalbumin. Gastroenterology 2007, 133:517-528.

93. Huibregtse IL, Marietta EV, Rashtak S, Koning F, Rottiers P, David CS, van Deventer SJ, Murray JA: Induction of antigen-specific tolerance by oral administration of Lactococcus lactis delivered immunodominant DQ8- restricted gliadin peptide in sensitized nonobese diabetic Abo Dq8 transgenic mice. J Immunol 2009, 183:2390-2396.

94. Takiishi T, Korf H, Van Belle TL, Robert S, Grieco FA, Caluwaerts S, Galleri L, Spagnuolo I, Steidler L, Van Huynegem K, et al: Reversal of autoimmune diabetes by restoration of antigen-specific tolerance using genetically modified Lactococcus lactis in mice. J Clin Invest 2012, 122:1717-1725.

95. Robert S, Gysemans C, Takiishi T, Korf H, Spagnuolo I, Sebastiani G, Van Huynegem K, Steidler L, Caluwaerts S, Demetter P, et al: Oral delivery of Glutamic Acid Decarboxylase (GAD)-65 and IL10 by Lactococcus lactis reverses diabetes in recent-onset NOD mice. Diabetes 2014.

96. Steidler L, Neirynck S, Huyghebaert N, Snoeck V, Vermeire A, Goddeeris B, Cox E, Remon JP, Remaut E: Biological containment of genetically modified Lactococcus lactis for intestinal delivery of human interleukin 10. Nat Biotechnol 2003, 21:785-789.

97. Graham-Rowe D: Lifestyle: When allergies go west. Nature 2011, 479:S2-S4

98. Okada H, Kuhn C, Feillet H, Bach JF: The 'hygiene hypothesis' for autoimmune and allergic diseases: an update. Clin Exp Immunol 2010, 160:1-9.

doi:10.1186/1475-2859-13-S1-S11

Cite this article as: Robert and Steidler: Recombinant Lactococcus lactis can make the difference in antigen-specific immune tolerance induction, the Type 1 Diabetes case. Microbial Cell Factories 2014 13(Suppl 1):S11.

\section{Submit your next manuscript to BioMed Central and take full advantage of:}

- Convenient online submission

- Thorough peer review

- No space constraints or color figure charges

- Immediate publication on acceptance

- Inclusion in PubMed, CAS, Scopus and Google Scholar

- Research which is freely available for redistribution
C Biomed Central 